\title{
Physico-chemical characteristics of the Agüera River (Spain) during an unusual hydrologically period
}

\author{
A. Elóseguil \\ J. Pozo'
}

Keywords : River, Basque Country, drought, physico-chemical characteristics.

Spatial-temporal changes in the physico-chemical characteristics of the Agura river (Basque Country and Cantabrian region, Spain) were studied over six months, a period that included a long period of unusual drought and the return to more normal hydrological conditions. The chemical composition of the water was affected by water flow. It was influenced either directly through the drainage characteristics at the level of different parts of the surrounding basin, or indirectly through the action of biotic communities on their environment. From these results, some spatial and/or temporal models have been developed for the dynamics of the different variables in this study.

\section{Caractéristiques physico-chimiques de la rivière Agüera (Espagne) au cours d'une période hydrologique inhabituelle}

Mots clés : Rivière, Pays-Basque, sècheresse, caractères physico-chimiques.

Les changements spatio-temporels des caractéristiques physico-chimiques de la rivière Agüera (Pays-Basque et Région Cantabrique, Espagne) ont été étudiés pendant 6 mois, englobant une partie d'une longue période de sécheresse inhabituelle, et le retour à des conditions hydrologiques plus normales. La composition chimique de l'eau était contrôlée par le débit de la rivière. Elle est influencée soit directement par l'écoulement au niveau de différents compartiments du bassin versant soit indirectement par l'action des communautés biotiques sur leur environnement. De ces résultats, des modèles spatio et/ou temporels ont été décrits pour la dynamique des différentes variables étudiées.

\section{Introduction}

Rivers are systems that transport and process materials exported by terrestrial ecosystems, normally seawards. In this sense, they can provide integrated information about the whole of the biotic and abiotic processes occurring in the fluvial basin (Rochelle et al. 1989, Sabater et al. 1990). The relative importance of these functions depends upon a broad series of factors among which physiographic, climatic and biological factors can be cited (Schumm 1988). Man is today a powerful modellator of the environment, and accordingly, his activity may have great influence on the characteristics of river systems (Davis 1987, Reynolds et al. 1989).

\footnotetext{
1. Laboratorio de Ecologia. Departamento de Biologia Vegetal y Ecologia. Facultad de Ciencias. Universidad del País Vasco/Euskal Herriko Unibertsitatea. Apdo. 644, Bilbao 48080. Spain.
}

Among all the factors cited above, climate, as a regulator of the water flow, exerts an importat control over the fluvial communities (Scrimgeour \& Winterbourn 1989); very often they have to face relatively impredictable changes in their environment, which can affect their biomass, the structure and composition of sediments, the physico-chemical composition of water, etc. (Reiter 1986). Therefore, it is always interesting to study the response patterns of different reaches of a river to changes in their hydrological regime.

Northern Iberian rivers flowing to the Cantabric sea are characterised by their heavy slope and short length, and, in contrast to those flowing to the Mediterranean, do not show important temporal variations in their discharge rates. Up to date, the studies carried out in different catchments of the Basque Country (Euskoiker 1988) have contributed only with low-periodicity data of several 
physico-chemical variables, but thcy have not allowed a detailed analysis of short-term changes in the rivers. In this paper, we present the results of a study of the physico-chemical properties of the river Agüera, carried out during the final phase of a long and unusual dry period and the beginning of more usual hydrological conditions.

\section{Study site}

The Aguiera river (Basque Country-Cantabria, Spain) drains a basin of $14,500 \mathrm{Ha}$ (Fig. 1), whose highest point is mount Burgueño (1 $044 \mathrm{~m}$ a.s.l.). The river runs $30 \mathrm{~km}$ until it reaches the sea. From the geological point of view, the basin lies over a Cretaceous, mostly siliceous substrate, covered with sandstones and clay, except in a broad central strip, where marls and very thick, karsufied limestones predominate. Several springs can be found in this zone, which indicate the importance of the aquifers (Cruz San Julián et al., 1986). Main land uses are grasslands and agricultural lands $(29 \%)$, forestal plantations (mostly pine, $34 \%$, and Eucalyptus, $16 \%$ ), and autochtonous forests, mostly oak (10 ${ }^{\circ} \%$ in siliceous land. cantabric evergreen oak $(7 \%)$ in calcareous substrate, and alder in the margins of the river channels. Population density is low, and the principal huntan activities are agriculture, livestock, and forestal sectors. Human settlements are disperse, and the brggest villages are those of Trucios, Villaverde, Gurie:s and Trebuesto. The climate is humidoceanic, with an annual preciptation of $1,650 \mathrm{~mm}$, almost totally in form of rain, regularly distributed throughout ths year. The annual mean temperature is 11 . C, and the monthly mean varies between $5.8^{\circ} \mathrm{C}$ in Ianuary and $17^{\circ} \mathrm{C}$ in August.

During 1988-1989 an unusual drought was registered, as the habirual fall-winter rains failed. The waterflow maintened low ievels, reaching its mininual values in January-February (Fig. 2). This drv period ceased suddenly at the end of February, and the waterflow was high during March. April was a very rainy month, reaching the highest discharge of the last five years on 4 th April.

\section{Methodology}

Ten stations located along the whole river (Table 1), were sampled biweekly during six months (November 88-May 89). The following variables were determin:d in situ : cross section of the channel. velocity distribution of the water (flowmeter General Oceanuci, pH (pHmeter Scharlau Hi 8424). temperature, conductivity renductivimeter WTW

Table 1. Marn tharater islos at the sampling stations.

\begin{tabular}{llllll}
\hline Station & $\mathrm{Km}$ & Elevation $(\mathbf{m})$ & slope & Order & Vegetation \\
\cline { 5 - 6 } 1 & 1 & 450 & 19.05 & 1 & Mixed forest \\
2 & 3.3 & 230 & 3.08 & 2 & Pines \\
3 & 4 & 210 & 1.7 & 3 & Meadows \\
$\mathbf{4}$ & 7.3 & 150 & 0.71 & 3 & Meadows \\
5 & 10.5 & 130 & 0.69 & 3 & Meadows \\
6 & 12 & 120 & 0.86 & 3 & Meadows \\
7 & 15.5 & 80 & 0.8 & 3 & Eucalyptus \\
$\mathbf{8}$ & 18.5 & 60 & 1.33 & 3 & Meadows \\
9 & 24 & 15 & 0.44 & 3 & Meadows \\
10 & 25.3 & 5 & 0.44 & 3 & Meadows \\
\hline
\end{tabular}




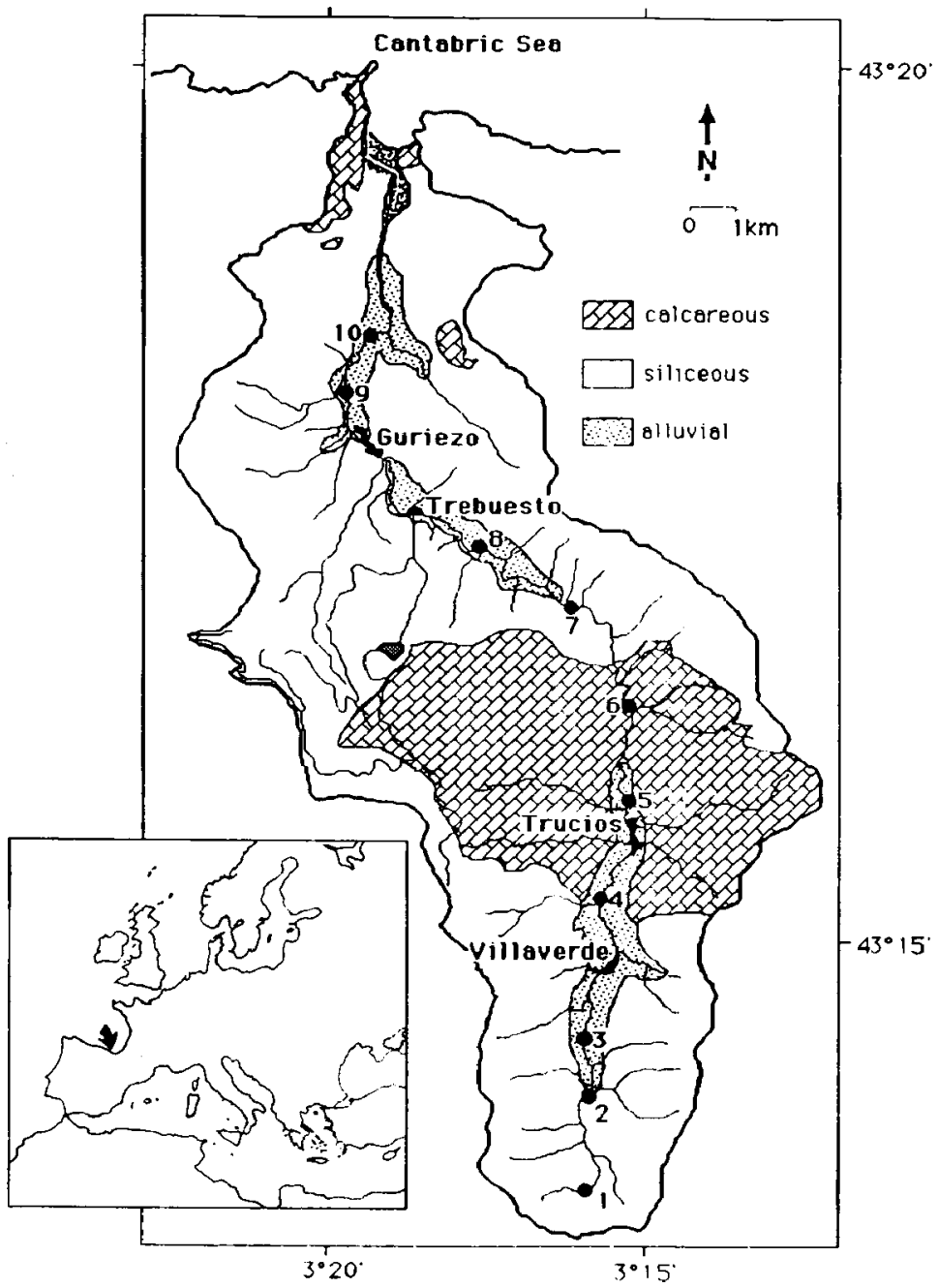

Fig. 1. The Agüera river basin. Main geological features and human settlements are showed. Numbers correspond to the sampling sites. 

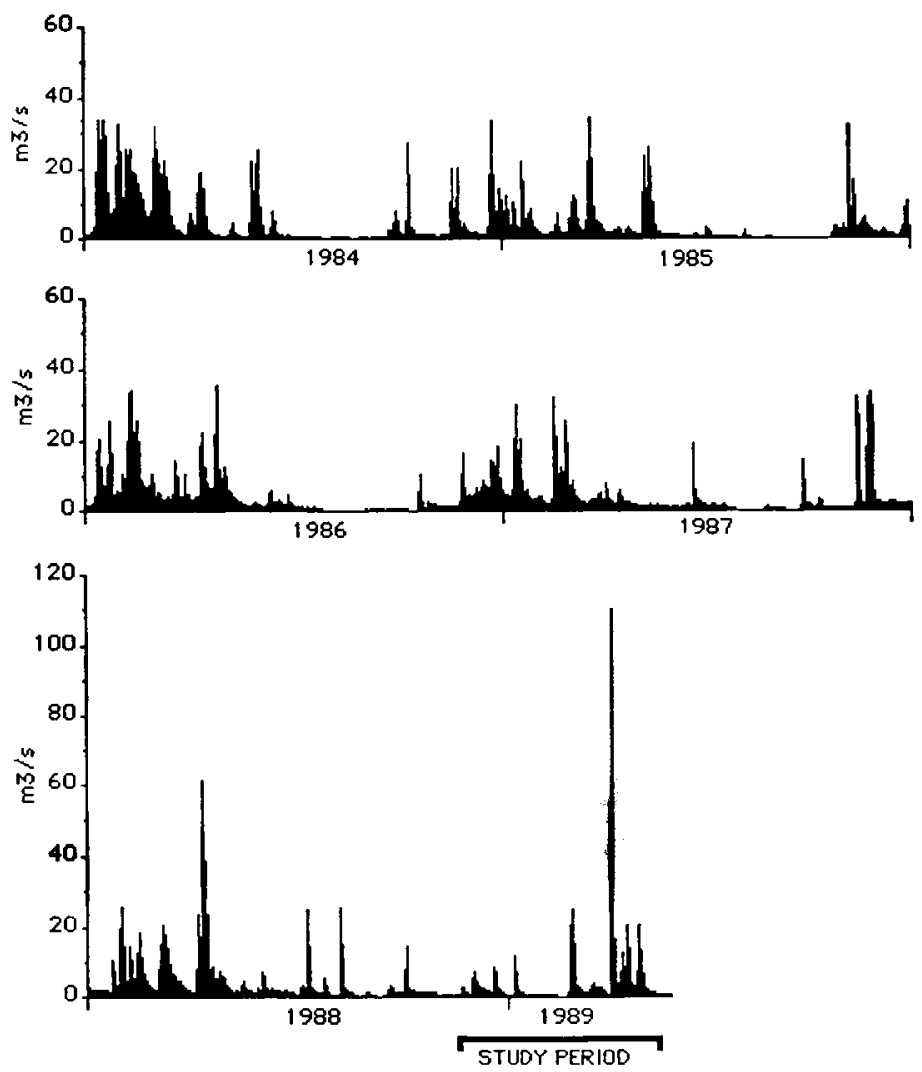

Fig. 2. Discharge variations in Aguiera river from 1984 10 1989. Compare the study period with the values in the upper part of the figure.

LF90), concentration and percentage of saturation of oxygen (oxymeter WTW Oxi96). Water samples were taken in plastic bottles, and immediately introduced in a cool place to be carried to the laboratory. Samples for the determination of phosphate were also preserved in cool conditions, but in glass bottles.
The following variables were determined according to the Standard Methords (APHA 1980) : alkalinity and hardness, by titration ; magnesium, sodium and potasium by atomic absorption spectrophotometry ; calcium by calculation from the difference obtained in the analysis of hardness and magnesium ; soluble reactive silicate, nitrate, nitrite, 
ammonia and reactive phosphorus by spectrophotometry; sulphate by the turbidimetric method; fine seston ( $<1 \mathrm{~mm}$ ), after filtration (Whatman $\mathrm{GF} / \mathrm{C})$, oven drying $\left(70^{\circ} \mathrm{C}\right)$ and calcination $\left(450^{\circ} \mathrm{C}\right)$. Measurements of alkalinity and hardness were conducted immediately and the remaining samples were maintained at $4^{\circ} \mathrm{C}$ until their processal. Whenever the analysis was impossible to be made within the first 24 hours, the samples were kept frozen at $20^{\circ} \mathrm{C}$.
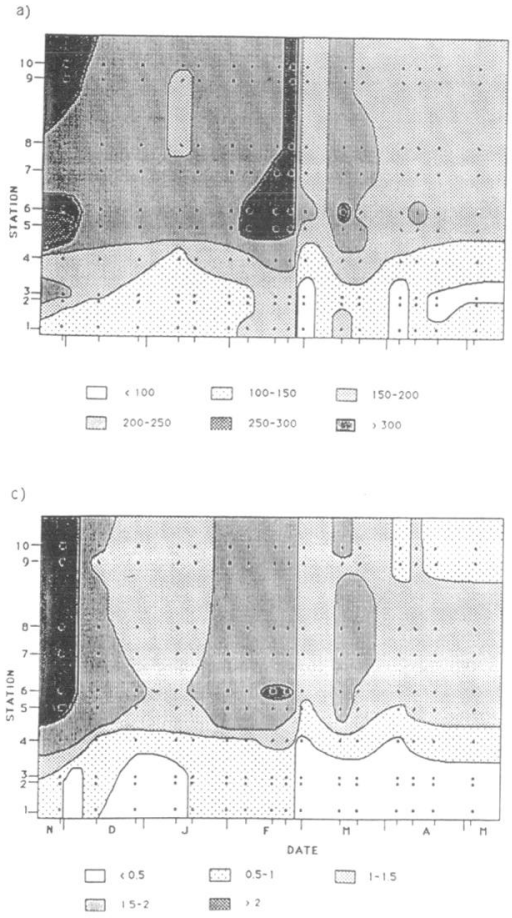

\section{Results}

A clear longitudinal gradient can be seen in the variables associated with the mineralization of waters, conductivity, hardness, and alkalinity (Fig. 3a, b, c). They show notable increases around station 4 , where the river passes from the siliceous to the calcareous part of the basin. The $\mathrm{pH}$ (Fig. 3 d) shows a similar pattern, but it diminishes in the final reaches of the river, as a consequence of the contribution of low-mineralization affluents.

b)
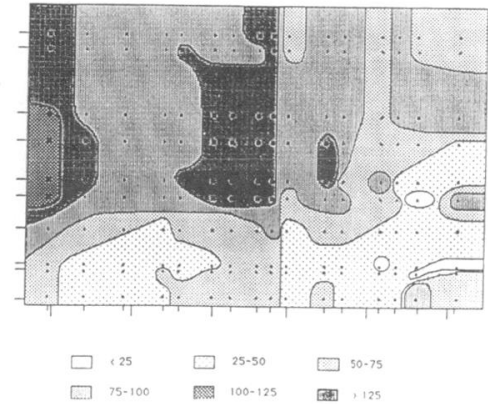

d)
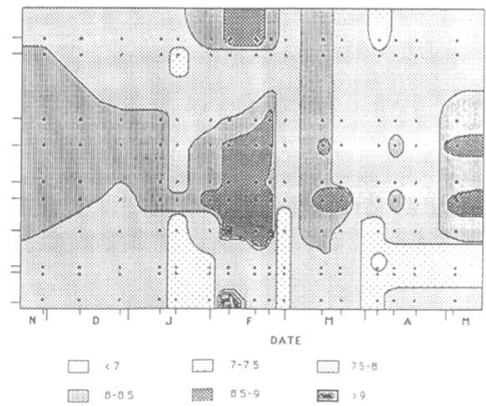

Fig. 3. Spatio-temporal variations during the study period. a) conductivity $(\mu \mathrm{S} / \mathrm{cm})$; b) hardness (meq/l) ; c) alkalinity (meq/l) ; d) pH. 
This condition becomes more and more evident as the flow decreases in winter, and suffers a drastic change with the floods in February-April, with the result of a remarkable homogenization of the river at high flows.

The oxygen saturation (Fig. 4 a) also shows important temporal variations. On the one hand, strong oversaturation levels are found in station 1 . We associate this phenomenon with waterfalls just above the measuring site. On the other hand, at the end of the dry period, very high partial tensions of

a)

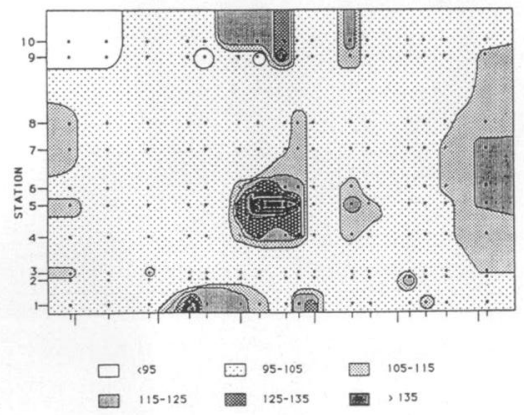

c)

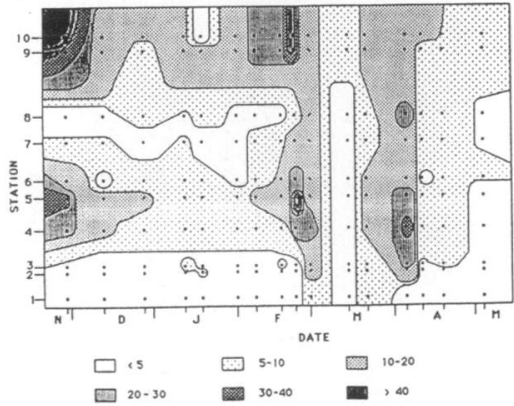

oxygen are detected in the intermediate and final stations, probably caused by the metabolism of benthic communities. The saturation of oxygen is almost reached at stations 7 and 8 , partly due to the steeper sides, and to the SE-NW direction of the streambed, which determines low incident irradiences during the winter months, and partly to their greater turbulence, involving a faster gaseous interchange with atmosphère. In high-flow periods, the oxygen concentration is around saturation throughout the river.

b)

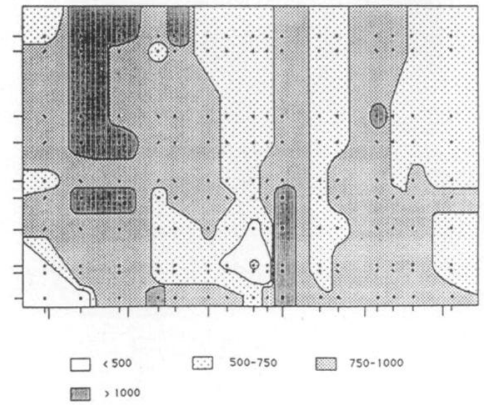

d)

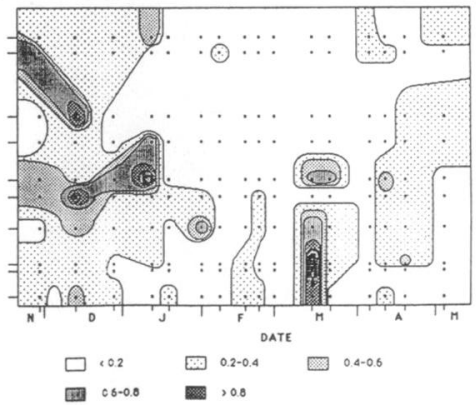

Fig. 4. Spatio-temporal variations during the study period. a) percentage of oxygen saturation; b) nitrate concentration ( $\mu \mathrm{gN} / \mathrm{l})$; c) nitrite concentration $(\mu \mathrm{gN} / \mathrm{l})$; d) ammonia concentration $(\mu \mathrm{N} / \mathrm{l})$. 
a)
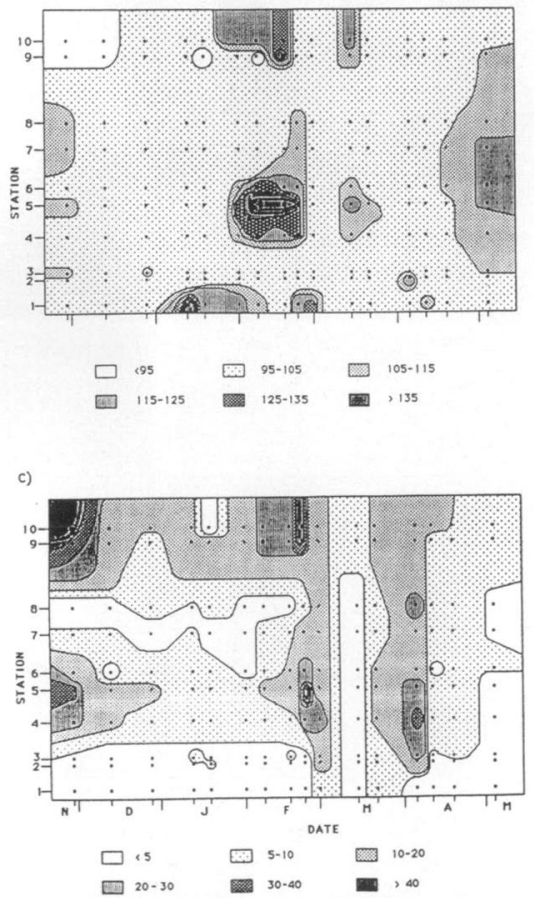

b)

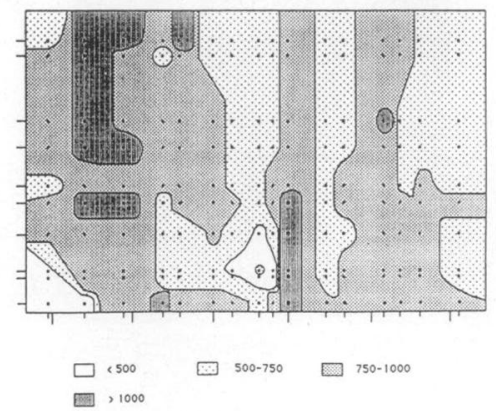

๑)

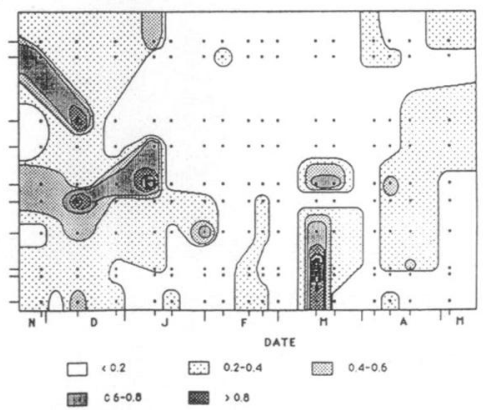

Fig. 5. Spatio-temporal variations during the study period. a) phosphate concentration $(\mu g \mathrm{P} / \mathrm{l}) ; \mathrm{b})$ silicate concentration (mgSi/l) ; c) suspended fine particulate matter $(\mathrm{mg} / \mathrm{l})$; d) percentage of organic content of FPM.

Nitrate (Fig. 4 b) seems to reflect two overlapped phenomena. Its levels are highest in the period November-January, decreasing from there on ; this seems to reflect a seasonal rhythm. On the other hand, its concentration increases with high discharges, mostly in headwaters. Nitrite (Fig. 4 c) usually appears in low concentration, reaching its highest values downstream from the human settlements, i.e., stations 4, 5, 9 and 10 . Furthermore, a temporal variation is observed, as the content of this nutrient decreases during January-February, and increases again when the discharge rises. Ammonia (Fig. 4 d) shows a less regular pattern, possibly due to the very local factors that govern its concentration.

Phosphate (Fig. 5 a) also reflects the importance of the wastewaters associated with the villages of Villaverde, Trucios and Guriezo, and the subsequent recovery process. Silicate (Fig. 5 b), reaches its 
highest values in the headwaters, because of the substrate of this part of the cachment. It should also be stressed the occurence of low concentrations in medium and low reaches, coinciding with minimal discharges, and in consequence, with a maximum in algal blooming.

During the low flow period up to last February, the concentrations of suspended fine particulate matter (Fig. 5 c) are relatively low, and lack a clear spatial pattern, because of the importance of sedimentation over the transport processes. It increases in spates, mainly in the headwaters. In general, with high flows, the inorganic fraction of seston is more important (Fig. 5 d). Station 9 generally maintains the highest proportion of organic matter, as a consequence of the urban impact.

The relationships existing between the study variables are presented in Table 2 as a previous step to the overall description of our results. This table shows the sign of significant relations between pairs of parameters for each station (lower part of the diagonal) during the whole study period, as well as the global correlation values (upper part). As it could be expected, the variables indicating the mineralization appeared negatively correlated to silica. The high correlation between conductivity, alkalinity, and hardness is a constant all along the river. The diluting effect of floods can be seen in the general negative correlation between flow and conductivity. Furthermore, the discharge is the principal determinant of the amount of seston and suspended organic matter in all the stations but 9 . Flow and phosphate maintain a positive correlation in the cleanest reaches. This nutrient shows a positive correlation with nitrite in all the stations but 1,7 and 8 . Nitrate is not usually correlated with the other nutrients, which suggests a different control mechanism.

In order to ascertain more clearly the causes of the variability observed in the physico-chemical characteristics of the water, and with the purpose of detecting possible general trends, we have performed Principal Components Analysis (PCA) (Lebart \& Morineau 1982) with the whole pool of data. The first three axes explain the $64 \%$ of the sample variance.

Main contributors to axis I (Fig. 6) are conductivity, alkalinity, calcium, hardness and $\mathrm{pH}$, in the negative side, and silicate, in the positive one. In consequence, we can interpret this axis as a factor of mineralization of the water. Thus, samples from stations 1-3 are situated in the right end, whereas the most mineralized samples are those from stations 5, 6, 9 and 10 , especially during lowest discharges. Axis II is under the influence of FPOM and FPM in its negative side. We interpret this axis as the increase in discharge, i.e., the axis of loods. In fact, the 10th and 13th samplings correspond to the highest flows registered, and all the samples from those days, no matter the station in which were taken, appear in the lowest part of the figure.

The distribution of the samples in the plane of axes I and II (Fig. 7), corroborate our interpretation. Samples taken in the days with the lowest flows appear in the highest part of the graph. The greatest dispersion occurs in station 9, which indicates that the seston content of this station is very

Table 2. Correlation matrix for selected variables. Lower part of the diagonal : sign of the significant correlations for each station. Upper part : global value of the correlation.

\begin{tabular}{|c|c|c|c|c|c|c|c|c|c|c|c|c|c|}
\hline $\mathrm{pH}$ & • & 0.68 & 0.61 & -0.14 & 0.65 & 0.58 & -0.59 & -0.16 & 0.12 & -0.05 & 0.25 & -0.35 & -0.37 \\
\hline CON & $++++\infty \cdot 1$ & & 0.29 & -0.09 & 0.96 & 0.91 & -0.74 & 0.01 & 0.43 & -0.05 & 0.44 & -0.30 & -0.27 \\
\hline SAT & $* \cdots+\cdots$ & & & -0.11 & 0.22 & 0.22 & -0.39 & -0.11 & 0.16 & -0.17 & 0.32 & -0.56 & -0.03 \\
\hline FLO & $\ldots-\cdots$ & nas & + & & -0.01 & -0.06 & 0.01 & 0.06 & 0.07 & -0.10 & 0.05 & 0.24 & 0.28 \\
\hline ALK & $44+4$ & $\ldots+\ldots+\cdots+\ldots$ & + & - & & 0.92 & -0.77 & 0.05 & $\overline{0} .4 \overline{0}$ & -0.07 & 0.43 & -0.28 & -0.25 \\
\hline HAR & 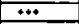 & $0+0+\cdots+0+\cdots$ & . & $-\ldots \ldots$ & 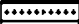 & & -0.73 & 0.03 & 0.38 & -0.08 & 0.40 & -0.28 & -0.24 \\
\hline SL & $=-$ & $\ldots$ & -- - & --+ & 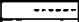 & $+\cdots$ & & 0.11 & -0.46 & 0.16 & -0.48 & 0.09 & 0.05 \\
\hline NAT & $-\because-$ & - & -- & +4 & $\because$ & -- & -- & & 0.14 & 0.07 & 0.04 & 0.18 & 0.16 \\
\hline NIT & $=$ & $\cdots$ & $\cdot$ & $+\cdots$ & $=$ & - & +- & +4 & & -0.07 & 0.86 & 0.25 & 0.36 \\
\hline$A M D$ & & & - & & 1 & + & 1 & & & & -0.09 & -0.09 & -0.12 \\
\hline & $\cdots$ & $=-\cdots$ & + & $\cdots \quad \cdots$ & $\because \quad \cdots \quad \bullet$ & $\cdot \quad \cdots$ & $\cdots$ & $\cdots$ & $+\cdots+\cdots \quad \cdots$ & & & 0.19 & 0.31 \\
\hline SES & 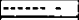 & $=\cdots$ & & $+\cdots+c+\infty+\infty+0$ & $\ldots$ & $-\quad-$ & $=$ & +1 & $*+\quad$ & & $1 .$. & & 0.94 \\
\hline $\mathrm{FOM}$ & $\ldots$ & $=-$ & & $10+0,+\cdots+4+4$ & $-\cdots$ & & - & $+4+$ & $\ldots+\infty$ & & $\ldots+\cdots$ & $+\ldots+\ldots+\ldots$ & \\
\hline & $\mathrm{pH}$ & CON & SAT & FLO & ALK & HAR & SIL & NAT & NIT & $A M O$ & PHO & SES & FOM \\
\hline
\end{tabular}




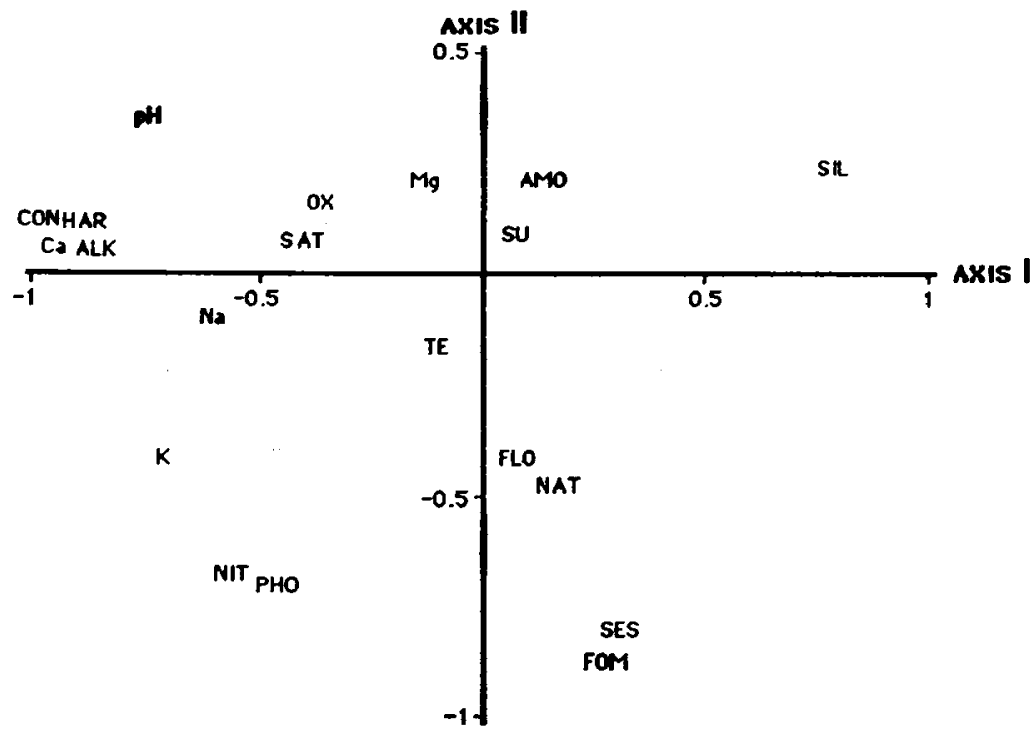

Fig. 6. Situation of the measured variables in he plane of axis I and II resulting from PCA. TE : temperature ; pH : pH ; CON : conductivity ; SAT : oxygen saturation ; OX ; oxygen concentration ; FLO : waterflow ; ALK : alkalinity ; HAR : hardness ; Ca : calcium ; $\mathrm{Na}$ : sodium ; $\mathrm{K}$ : potassium ; $\mathrm{Mg}:$ magnesium ; SIL : silicate ; NAT : nitrate ; NIT : nitrite ; AMO : ammonia ; PHO : phosphate ; SU : sulphate ; SES : seston ; FOM : fine particulate organic matter.

variable, although always high. On the other hand, stations 7 and 8 show, except for spates, a trend to be situated in a narrow band in the positive part of axis II. This phenomenon is in agreement with the self-depuration occurring in this reach.

\section{Discussion}

Differences in the lithological composition of the Agüera river basin are responsable for a pronounced longitudinal gradient in the parameters associated with water mineralization, mostly in dry periods, when the contact between the water and mineral substrate is most intense. In any case, there are values of $\mathrm{pH}$ that are explainable not only by the kind of substrate, but also by metabolic processes of the community. This is especially evident during February, a period of minimal flows, that, possibly in combination with the elongation of the day, make easier the proliferation of benthic algae in medium reaches. In this part of the river, important algal masses, dominated by Cladophora sp., can be observed. The metabolism of these producers could be the responsible for high $\mathrm{pH}$ values (Margalef 1983), as those found in stations 4-7. This is also deduced from the diel dynamics of this parameter (unpubl. data). In lower reaches (station 9) this effect is not so evident, possibly because it is counteracted by the decomposition of organic materials of urban origin. 


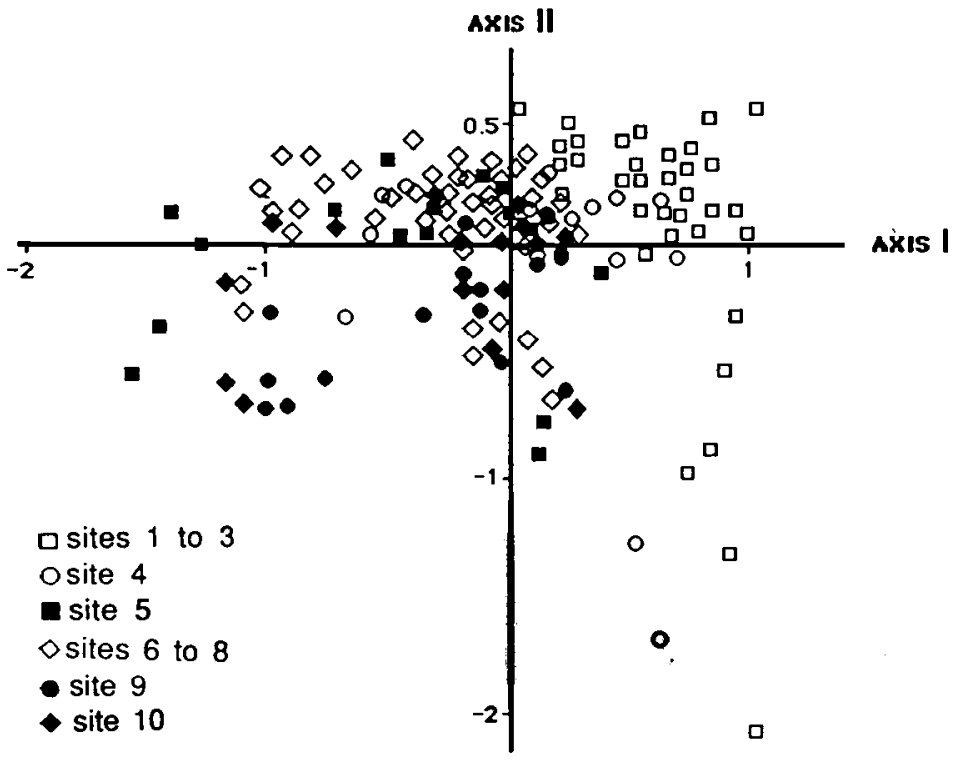

Fig. 7. Situation of the samples in he plane of axis I and II resulting from PCA.

The results of this work have allowed us to deduce spatial and/or temporal patterns in the dynamics of the different non-conservative variables studied. Nitrogen, under its different forms, constitutes one of the essential nutrients in rivers. Biological transformations of nitrogen include the uptake by algae and microbia, fixation and denitrification (Richey et al. 1985, Hill 1988), but estimates of the relative importance of these processes in different rivers do not coincide. In our case, nitrate concentration increased with high discharges, mostly in the headwaters, probably due to the greater leakage of soils (Mc Diffet et al. 1989). Several authors (e.g. Neill 1989) stress the importance of the agricultural practices, like the fertilization of ploughed land, in the control of nitrate levels in rivers. From our results it can not be deduced any clear relationship between agricultural land and nitrate concent ration. This is explainable by the kind of agricultural practices in this area, in which meadows are the most important crop, with not very intensive application of mineral fertilizers. Nitrite maxima appear near the main urban settlements. Also, as the importance of producers increases in February, maximum values of nitrite decrease, possibly helped by the oxidizing conditions that prevail at that moment. When rainfall increases, nitrite maxima appear near the villages, as a consequence of the leaching of rivershore areas. The dynamics of ammonia are more complex, and in this sense, we cannot forget the several sources af ammoniacal nitrogen (Schuurkes \& Mosello 1988), which obscures their interpretation. 
Phosphate clearly reflects the influence of the villages, but with this sampling strategy we cannot ascertain its importance in relation with other possible factors of variation, as the agricultural practices in karstic areas (Troelstrup \& Perry 1989), the urbanizations (Osborne \& Wiley 1988) or the biological uptake (Corning et al. 1989, Mulholland et al. 1983). In the Agüera river, self-purification processes (Vymazal 1988) are evident in the reach where urban inputs dissapear, that is, in the reach $6-8$, during low-flow periods. According to Corning et al. (1989), the assimilation rate of phosphate by the benthos does not change along the river. If that is the case of our system, we should explain the decrease in medium-low reaches as a mere reflection of the disappearance of phosphorus inputs ; the high capacity of self-purification in the river would be exceeded solely by important inputs around villages. On the other hand, Cosser (1989) mentions the importance of particulate phosphorus. A part of the decrease in the charge of phosphorus could be due to the sedimentation of seston, which would be favoured in the reach $6-8$, that seems to be especially retentive.

During February, the high organic content of the seston in medium-low reaches in coincidence with the vicinity of villages, seems to be due to the low flows of this dry period, that would concentrate the sewage. The drift of algae in medium reaches could be added to this effect, as these organisms were particularly abundant during this period. We can deduce that river discharge is the principal responsable for the FPOM concentrations, in agreement with other works (Cuffney \& Wallace 1989, Grubaugh \& Anderson 1989). These authors report that most of the yearly transport of the organic matter occurs in a few events.

The Principal Components Analysis stresses the spatial organization of the Agüera river. It could be divided in four main zones. In the headwaters, up to station 3, most of the catchment area is forested, the slope is high, and human activities minimal ; these properties determine, together with the lithological composition of substrate, low nutrient concentrations in the water, and a scarce importance of primary producers. A second zone would correspond to the reach between stations 4 and 6 . Here, both the population density and the intensity of agricultural practices rise. All this, together with the smaller slope and the lower forest cover, makes possible, under medium and low flow conditions, the blooming of dense algal populations, even in winter months. In this sense, Sheldon \& Taylor (1982) showed, in artificial rivers, the relative constance of algal production during the year, in contrast with the more seasonal effect of macrophytes. In the third zone, situated between stations 6 and $\mathbf{8}$, the physiographic characteristics of the reach determine a process of self-purification. In fact, in this part, human activities diminish, the slope rises, streamsides are steeper, and the streambed consists of a series of riffles and pools, that makes this a highly retentive reach (Cummins et al. 1983, Webster et al. 1987). The last part of the river, located between station 8 and the mouth, is again more open, more humanized, and as a consequence, nutrient levels increase. This spatial organization is changed by the discharge, with floods producing an homogenization of the chemical characteristics along the longitudinal axis of the river, as a consequence of the diluting effect of the water, and the disturbance of benthic communities.

\section{Acknowledgements}

This work has been supported by the University of the Basque Country (research project UPV 118.310-0067/88). Thanks to Mr. I. Madariaga for improving the English.

\section{References}

Apha. 1980. - Standard Methods for examination of water and wastewater, 15th. edition. American Public Health Association. Washington. $1134 \mathrm{p}$.

Corning R.E., Duthie H.C. \& Paul B.J. 1989. - Phosphorus and glucose uptake by seston and epilithon in boreal forest streams. J.N. Am. Benthol, Soc., $8: 123-133$.

Cosser P.R. 1989. - Water quality, sediments and the macroinvertebrate community of residential canal estates in SouthEast Queensland, Australia ; a multivariate analysis. Wat. Res., 23 : 1087-1097.

Cruz-Sanjulián J.J., Garcia-Latorre F. \& Ibarra-Lozano V. 1986. - Delimitación del sistema kárstico del manantial de Itur. riotz (Trucios, Vizcaya) ; su caracterización a partir del análisis del hidrograma. Boletin Geológico y Minero, XCVI]VI : $92-102$.

Cuffney T.F. \& Wallace J.B. 1988. - Particulate organic mat ter export from three headwater streams : discrete versus continuous measurements. Con. J. Fish. aqual. Sci., 45 : 2010-1016.

Cummins K.W, Sedell J.R., Swanson F.J., Minshall G.W., Fisher S.G., Cushing C.E., Petersen R.C. \& Vannote R.L. 1983. - Organic matter budgets for stream ecosystems : problems in their evaluation. In : Barnes J.R. \& Minshall G.W. (eds.) Stream ecology. Application and testing of general ecological theory. Plenum Press. New York : 299-354. 
Davis E.A. 1987. - Chaparral conversion and streamflow : nitrate increase is balanced mainly by a decrease in bicarbonate. Wat. Resour. Res., $23: 215-224$.

Euskoiker. 1988. - Coracterización fisico-quimica y biologica de la red hidrográfica de Bizkaia. Informe final. Diputación Foral de Bizkaia. Bilbao.

Grubaugh J.W. \& Anderson R.V. 1989. - Upper Mississipi River : seasonal and floodplain forest influences on organic matter transport. Hydrobiologia, $174: 235-244$.

Hill A.R. 1988. - Factors influencing nitrate depletion in a rural stream. Hydrobiologia, $160: 111-122$.

Lebart L. \& Morineau I.A. 1982. - Systeme portable pour l'analyse des données. SPAD. Cesia. Paris.

Margalef R. 1983, - Limnologia. Omega. Barcelona. $1010 \mathrm{p}$.

Mc Diffet W.F.. Breidier A.W., Dominick T.F. \& Mc Crea K.D. 1989. - Nutrient concentration-stream discharge relationships during storm events in a first-order stream. Hydrobiologia, 179: 97-102.

Neill M. 1989. - Nitrate concentrations in river waters in the South-East of Ireland and their relationship with agricultural practice. Wat, Res., 23 : 1339-1355.

Osborne L.L. \& Wiley M.J. 1988. - Empirical reationships between land use/cover and stream water quality in an agricultural watershed. J. Envir. Man., 26: 9-27.

Reiter M.A. 1986. - Interactions between the hydrodynamics of flowing water and the development of a benthic algal com. munity. J. Feshwat. Ecol., 3 : 511.517.

Reynolds B., Hornung M. \& Hughes S. 1989. - Chemistry of streams draining grassland and forest catchments at Plynlimon, mid-Wales. Hydrological Sciences - Journal des Sciences Hydrologiques, 34 : 667.686.

Richey J.S., Mc Dowell W.H.\& Likens G.E. 1985. - Nitrogen transformations in a small mountain stream. Hydrobiologia, $124: 129-139$.
Rochelle B.P., Liff C.I., Campbell W.G., Cassell D.L., Church M.R. \& Nusz R.A. 1989. - Regional relationships between geomorphic/hydrologic parameters and surface water chemistry relative to acidic deposition. $J$. Hydrol, $112: 103-120$.

Sabater F., Sabater S. \& Armengol J. 1990. - Chemical characteristics of a Mediterranean river as influenced by land uses in the watershed. Wat. Res, $24: 143-155$.

Schuum S.A. 1988. - Variability of the fluvial system in space and time. In : Rosswall T., Woodwansee R.G. \& Risser P.G. Scales and global change. John Wiley \& Sons. New York. 225-250.

Schuurkes J.A.A.R.\& Mosello R. 1988. - The role of external ammonium inputs in freshwater acidification. Schweiz. $Z$. Hydrol., $50: 71-86$.

Scrimgeour G.J. \& Winterbourn M.J. 1989. - Effects of floods on epilithon and benthic macroinvertebrate populations in an unstable New Zealand river. Hydrobiologia., $171: 33-44$.

Sheldon S.P. \& Tayor M.K. 1982. - Community photosynthesis and respiration in experimental streams. Hydrobiologia, $87: 3-10$.

Troelstrup N.H. \& Perry J.A. 1989. - Water quality in Southeastern Minnesota streams : observations along a gradient of land use and geology. Journal of the Minnesota Academy of Science, $55: 6-13$.

Vidal-Abarca M.R. 1990. - Los rios de las cuencas áridas y semiáridas : una perspectiva ecológica comparativa y de síntesis. Scientia gerundensis, $16: 219-228$.

Vymazal J. 1988. - The use of periphyton communities for nutrient removal from polluted streams. Hydrobiologia, 166 : $225-237$.

Webster J.R., Benfield E.F., Golladay S.W., Hill B.H., Hornick L.E., Kazmierczak R.F. \& Perry W.B. 1987. - Experimental studies of physical factors affecting seston transport in streams. Limnol, Oceanogr., 32 : 848-863. 